\title{
Influence of donor age on development of gonadal tissue from pouch young of the tammar wallaby, Macropus eugenii, after cryopreservation and xenografting into mice
}

\author{
D. Mattiske ${ }^{1}$, G. Shaw ${ }^{1}$ and J. M. Shaw ${ }^{2}$ \\ ${ }^{1}$ Department of Zoology, University of Melbourne, 3010, Australia; and ${ }^{2}$ Monash Institute of \\ Reproduction and Development, Monash University, Clayton, 3168, Australia
}

\begin{abstract}
Ovaries from a marsupial, the tammar wallaby (Macropus eugenii), were grafted into a eutherian recipient at known stages of development to ascertain whether normal development would occur. Xenografted ovaries from pouch young $<20$ days old, before the onset of meiosis, retained few germ cells and developed tubule-like structures reminiscent of seminiferous cords. Ovaries from 50-day-old pouch young, which contain primordial follicles, developed into antral follicles and corpora lutea within the eutherian host, and produced hormones that stimulated the reproductive tract of the host. The timing of onset of antrum formation and the progress of follicle development
\end{abstract}

were advanced relative to the timing of events in ovaries in situ. Frozen-thawed ovaries from 50-day-old donors developed into preantral follicles, but at a reduced rate and number. This finding shows that gonads of a marsupial species can develop as xenografts in a eutherian, forming large antral follicles. Accelerated follicular development in xenografts provides a potentially valuable model for studying the factors that control follicle development. Assisted reproduction of endangered marsupials may also be feasible using follicles from pouch young grown as xenografts in a eutherian host.

\section{Introduction}

Transplantation of ovaries has been used in reproductive biology since a surge of interest at the turn of the century (for a review, see Gosden, 1992; Nugent et al., 1997). Ovarian function, as assessed by hormone secretion, ovulation or fertility can be restored by ovarian autografts or allografts in a range of animals including mice (Candy et al., 1997), rats (Lara et al., 1991), cats (Wolfe and Wildt, 1996), sheep (Baird et al., 1999; Salle et al., 1999) and humans (Radford et al., 2001). Follicular growth and ovarian steroid secretion has also been examined in ovaries grafted into other members of the same species (allografts) or into different species (xenografts). Xenografts are usually transplanted into immunologically compromised mice or rats to avoid immune rejection. Functioning ovarian xenografts have been achieved for a range of species including cats (Gosden et al., 1994), marmoset monkeys (Candy et al., 1995), elephants (Gunasena et al., 1998) and humans (Newton et al., 1996; Oktay et al., 1998a; Weissman et al., 1999). Importantly, xenografts from humans and monkeys placed into mice developed antral follicles. Therefore, ovarian xenografting has the potential to allow follicles of a range of species to be studied under comparable conditions, as well as providing an alternative strategy for obtaining mature oocytes for subsequent research or assisted reproductive strategies. These techniques are potentially important for

Email:d.mattiske@zoology.unimelb.edu.au the preservation of rare and endangered species. Placing ovaries or pieces of ovarian tissue into a recipient of different hormonal status (Gosden, 1990; Telfer et al., 1990; Cox et al., 1996, 2000; Jenkin et al., 1996) also allows the requirements for follicular recruitment and development to be studied (Spears et al., 1996; Oktay et al., 1998a).

Conservation of rare species would be assisted further by methods aimed at optimizing strategies for storing and using genetic material. One way of achieving this is to store reproductive tissues using cryopreservation. Protocols that allow reproductive cells and tissues to be collected and stored in clinical, agricultural and animal husbandry programmes have been established. Furthermore, both cryopreservation and grafting have been evaluated as strategies for use with human ovarian tissue (Oktay et al., 1998b; Gosden, 2000; Shaw et al., 2000; Radford et al., 2001). Ovarian tissue is usually collected once the primordial follicles have entered their resting phase; however, fetal mouse ovaries, which contain predominantly primordial oocytes with no attached follicular cells, can survive cryopreservation and grafting, and complete development within another animal (Cox et al., 2000).

Although most cryopreservation studies have aimed at preserving mature oocytes or embryos, there is an advantage in storing ovarian tissue because it contains a large reserve of primordial follicles (Carroll et al., 1990; Candy et al., 1997; Newton et al., 1999a), which are less vulnerable to cryo-injury than are oocytes from antral follicles (Gosden, 1992; Van der Elst et al., 1992). Slices or fragments of 
ovarian tissue, rather than whole ovaries, are generally used for transplantation to minimize ischaemia after transplantation (Gosden, 1992). If the ovary is small, as in fetal or prepubertal animals, it can be transplanted intact as its size allows rapid revascularization.

Recent research highlights the possibility of storing primordial follicles and even prefollicular germ cells for subsequent in vivo or in vitro maturation (Oktay et al., 1998a; Salle et al., 1999; Weissman et al., 1999; Cox et al., 2000; Shaw et al., 2000). Despite the development of these techniques in eutherians, including marmosets (Candy et al., 1995), elephants (Gunasena et al., 1998) and humans (Oktay et al., 1998a,b; Newton, 1999b, Gook et al., 1999), cryopreservation and grafting of marsupial tissue has not been studied extensively. Wolvekamp et al. (2001) grafted wombat ovarian tissue into immunologically deficient rats and followed the development of the follicles to preantral stages; however, neither antral follicles nor mature oocytes were retrieved.

Reproductive physiology of the tammar wallaby, Macropus eugenii, is well understood. The pattern of oogenesis in the tammar wallaby is similar to that of eutherians, but differentiation of the ovary occurs postnatally. Germ cells can be identified first at day 17 of gestation (Ullmann et al., 1997) and proliferate mitotically until day 25 post partum. After day 25, germ cells in females progressively enter meiotic prophase, leading to the oocyte arrest at the diplotene or dictyate stage of meiosis I and incorporation into primordial follicles by day 50 post partum (Alcorn, 1975). Primordial follicles remain developmentally quiescent until approximately day 110 post partum when there is a steady growth of follicles until day 250 post partum, forming large antral follicles at puberty.

In this study, either fresh or cryopreserved ovaries from tammar wallabies were xenografted into severe combined inmmunodeficient (SCID) mice to determine the potential for application of these techniques in a marsupial species. Development was compared between ovarian tissue transplanted before the initiation of meiosis in germ cells, to determine whether there is a critical stage of development before which completion of oocyte proliferation and primordial follicle formation cannot occur outside the normal in situ environment, and after the initiation of primordial follicle development.

\section{Materials and Methods}

\section{Wallabies}

Tammar wallabies, Macropus eugenii, from Kangaroo Island were housed in open, grassy yards in our breeding colony in Melbourne, Victoria. Their diet was supplemented with lucerne cubes, oats and fresh vegetables. Head lengths of pouch young were measured with callipers and ages were determined from the growth curves as described by Poole et al. (1991).

Pouch young of the tammar wallaby were anaesthetized either by hypothermia by cooling on ice, if $<20$ days of age, or with Rompun (1 $\mathrm{mg} \mathrm{ml}^{-1}$ ) (Ilium Xylazil-20, Troy Laboratories, Sydney, NSW) and Ketamine (5 mg ml-1) (Parnell Laboratories, Alexandria, NSW) administered i.p. at $0.3 \mathrm{ml}$ per $20 \mathrm{~g}$ animal. Anaesthetized pouch young were killed by decapitation. The ovaries were dissected free and placed in sterile PBS at room temperature for immediate grafting, freezing or fixation in Bouin's fixative (Hopwood, 1996).

\section{Cryopreservation of ovaries by slow cooling}

Ovaries were cooled slowly by equilibrating tissue at $0^{\circ} \mathrm{C}$ on ice in a cryoprotectant solution of $1.5 \mathrm{~mol}$ dimethylsulfoxide $\mathrm{I}^{-1}$ (DMSO; Sigma, St Louis, MO) in PBS for $30 \mathrm{~min}$. Individual gonads were transferred into $1.5 \mathrm{ml}$ vials (Nunc, Kamstrupvej, Roskilde) and loaded into a programmable freezer (Freeze Control CL3000, Cryologic Pty Ltd, Mount Waverley, Victoria) maintained at $-6^{\circ} \mathrm{C}$. Vials were cooled to between $-5^{\circ} \mathrm{C}$ and $-7^{\circ} \mathrm{C}$, and were maintained at this temperature for $5 \mathrm{~min}$, after which they were seeded by touching the vial with a pair of forceps that had been cooled in liquid nitrogen. The vials were then cooled to $-40^{\circ} \mathrm{C}$ at a rate of $-0.3^{\circ} \mathrm{C} \mathrm{min}^{-1}$, before being plunged into liquid nitrogen.

Vials containing tissue that had been cooled slowly were immersed directly into a $37^{\circ} \mathrm{C}$ waterbath until the solution and tissues had thawed. Tissue was transferred into a Petri dish containing $3 \mathrm{ml}$ PBS with DMSO $\left(0.75 \mathrm{~mol} \mathrm{I}^{-1}\right)$ and sucrose $\left(0.25 \mathrm{~mol} \mathrm{I}^{-1}\right)$ solution at room temperature for 10 min. The tissue was then placed in $3 \mathrm{ml}$ PBS with sucrose $\left(0.25 \mathrm{~mol} \mathrm{I}^{-1}\right)$ for $10 \mathrm{~min}$, before being transferred into $3 \mathrm{ml}$ PBS (pH 7.2).

\section{Transplantation procedure}

Eight-week-old female SCID mice were purchased from Monash University Central Animal House. They were housed in micro-isolators, supplied with filtered air under positive pressure, and all food and water was sterilized by irradiation. Female SCID mice were ovariectomized under anaesthetic (0.2 mg Rompun $\mathrm{ml}^{-1}$ (Ilium Xylazil-20, Troy Laboratories) and $1 \mathrm{mg}$ Ketamine $\mathrm{ml}^{-1}$ (Parnell Laboratories) per $20 \mathrm{~g}$ body weight administered i.p.). Ovarian tissue from tammar pouch young was inserted gently through a 1-2 $\mathrm{mm}$ incision in the kidney capsule. After grafting, the skin was closed with Michelle clips and the mice were given $0.1 \mathrm{ml}$ Reverzine (Parnell Laboratories; $0.024 \mathrm{mg}$ in $0.1 \mathrm{ml}$ PBS administered i.v.) to counteract the anaesthetic.

\section{Experimental design}

Gonads were collected from female tammar pouch young of $15-20$ days $(n=15)$ and 50-70 days $(n=29)$ of age. Ovaries were grafted under the kidney capsule of female SCID mice either immediately after collection $(n=29)$ or after storage in liquid nitrogen $(n=15)$. All recipients were ovariectomized at the time of grafting. 
Recipients of non-frozen grafts were killed at $2(n=2), 4$ $(n=4), 8(n=4), 12(n=4), 16(n=5), 18(n=4)$ or 21 $(n=6)$ weeks after surgery so that the development of ovarian tissue could be examined over the same period taken by female tammar wallabies to reach puberty. Recipients of cryopreserved grafts from young donors (15-20 days old) were killed at $2(n=4)$ and $4(n=3)$ weeks after surgery to compare development of cryopreserved germ cells with those from non-frozen tissue. Recipients of cryopreserved grafts from older donors (50-70 days old) were killed at $8(n=2), 12(n=2)$ and $21(n=4)$ weeks after grafting to assess preantral and antral follicle formation after cryopreservation.

Ovaries from adult tammar wallabies and pouch young of $20,50,110,150$ and 210 days of age ( $n=2$ for each age) were also collected and fixed in Bouin's fixative for $24 \mathrm{~h}$ for comparison with development of grafted tissue. These ages correspond to critical stages of folliculogenesis as defined by Alcorn (1975). Oocytes are pre-meiotic at day 20 post partum and become incorporated into primordial follicles at day 50 post partum. Primordial follicles are recruited into the growing pool of follicles at day 110 post partum; early antral formation begins at day 150 post partum and preovulatory follicles are first observed at day 210 post partum

\section{Graft recovery}

Recipient mice were anaesthetized with $\mathrm{CO}_{2}$ and approximately $1 \mathrm{ml}$ of blood was collected by cardiac puncture. Plasma samples were also collected from control intact female mice $(n=2)$ and control ovariectomized female mice $(n=2)$. Recipient mice were killed by cervical dislocation; the kidneys were removed and the grafts located. When the graft had been in the host for $<16$ weeks, the grafts and uteri of the recipient were fixed in Bouin's fixative. Uteri from the control intact and control ovariectomized female mice were also fixed in Bouin's fixative. Ovarian tissue that had been grafted for $>16$ weeks was examined for antral follicles, which were carefully punctured with a $30 \mathrm{G}$ needle. Any oocytes found were measured and examined for the presence of polar bodies. The remaining graft tissue was fixed in Bouin's fixative.

\section{Histological analysis}

Tissues were fixed in Bouin's fixative for $24 \mathrm{~h}$, washed in three changes of $70 \%(\mathrm{v} / \mathrm{v})$ ethanol, embedded in paraffin wax, cut into serial sections of $7 \mu \mathrm{m}$, and stained with Harris' haematoxylin and eosin (Stevens, 1996). Ovarian grafts were cut into serial sections and every fifth section was examined for the presence of germ cells, developing follicles, corpora lutea, atretic follicles and vascularization of the ovary. Primordial germ cells were identified by their large ovoid shape, location within cell nests, vesicular nucleolus and pale staining cytoplasm. Germ cells were classified as either mitotic or meiotic (prophase 1) according to the criteria of Alcorn (1975). The number and type of follicles within the ovaries were estimated under a light microscope. Follicles were counted only when the nucleolus of the oocyte was in the field of view to ensure that no follicle was counted twice. Follicles were classified according to the method of Pedersen and Peters (1968) and grouped as primordial (type 3), preantral (types 4 and 5) or antral (types 6, 7 and 8). Follicles were classified as atretic if they contained granulosa cells with pyknotic nuclei, disrupted granulosa layers or oocytes that were degenerating. Follicles at a stage earlier than type 3 were not counted. Representative sections $(7 \mu \mathrm{m})$ were taken from the uteri of the host and examined for signs of stimulation. Volumes of the ovarian tissue were calculated by the point counting procedure (Gunderson et al., 1988a,b), using a coherent square test system $\left(\mathrm{I}(P)=10 \mathrm{~mm}, \mathrm{a}(P)=100 \mathrm{~mm}^{2}\right.$ ) (Weibel, 1979) on a Zeiss Axiovert $35 \mathrm{M}$ inverted microscope equipped with a Sony high-resolution video system.

\section{FSH assay}

Circulating concentrations of $\mathrm{FSH}$ were measured in female recipients of non-frozen ovaries from 50-dayold pouch young that had been grafted for $>18$ weeks $(n=7)$, using the method of Wreford et al. (1994). FSH concentrations were also measured in two intact and two ovariectomized female mice. All reagents were supplied by National Institute of Diabetes and Digestive and Kidney Diseases (NIDDKD; Bethesda, MD). Antisera was NIDDKanti-rFSH-S-11. Standards used were $0.39-25.0 \mathrm{ng} \mathrm{ml}^{-1}$ of NIDDK-rFSH-RP-2, and the tracer was NIDDK-rFSH-I-8. Assays were performed on $50 \mu \mathrm{l}$ samples of plasma diluted in assay buffer. The sensitivity of the assay was $<2.8 \mathrm{ng}$ $\mathrm{ml}^{-1}$ and $>44.0 \mathrm{ng} \mathrm{ml}^{-1}$ for the $50 \mu \mathrm{l}$ samples.

\section{Statistical analysis}

When applicable, results are presented as the mean \pm SE. FSH concentrations between graft recipients and control animals were compared using two-sample $t$ tests. Results were considered significantly different at $P<0.05$.

\section{Results}

\section{Control ovaries}

Ovaries from 20-day-old pouch young contained a clearly defined cortex and medulla. The cortex was composed of germ cell nests separated by thin bands of stroma. Most primordial germ cells were in interphase and some germ cells were undergoing mitotic divisions. No germ cells were observed at meiosis. The medulla consisted of a number of densely packed cords, known as rete cords, possessing cells with dark staining nuclei.

By day 50 post partum, germ cells located in the inner region of the cortex started to differentiate into primordial follicles, which consisted of an oocyte surrounded by a single layer of flattened granulosa cells. Germ cells nearest to the medulla were in early meiotic prophase, and most of the germ cells located peripherally remained in interphase 

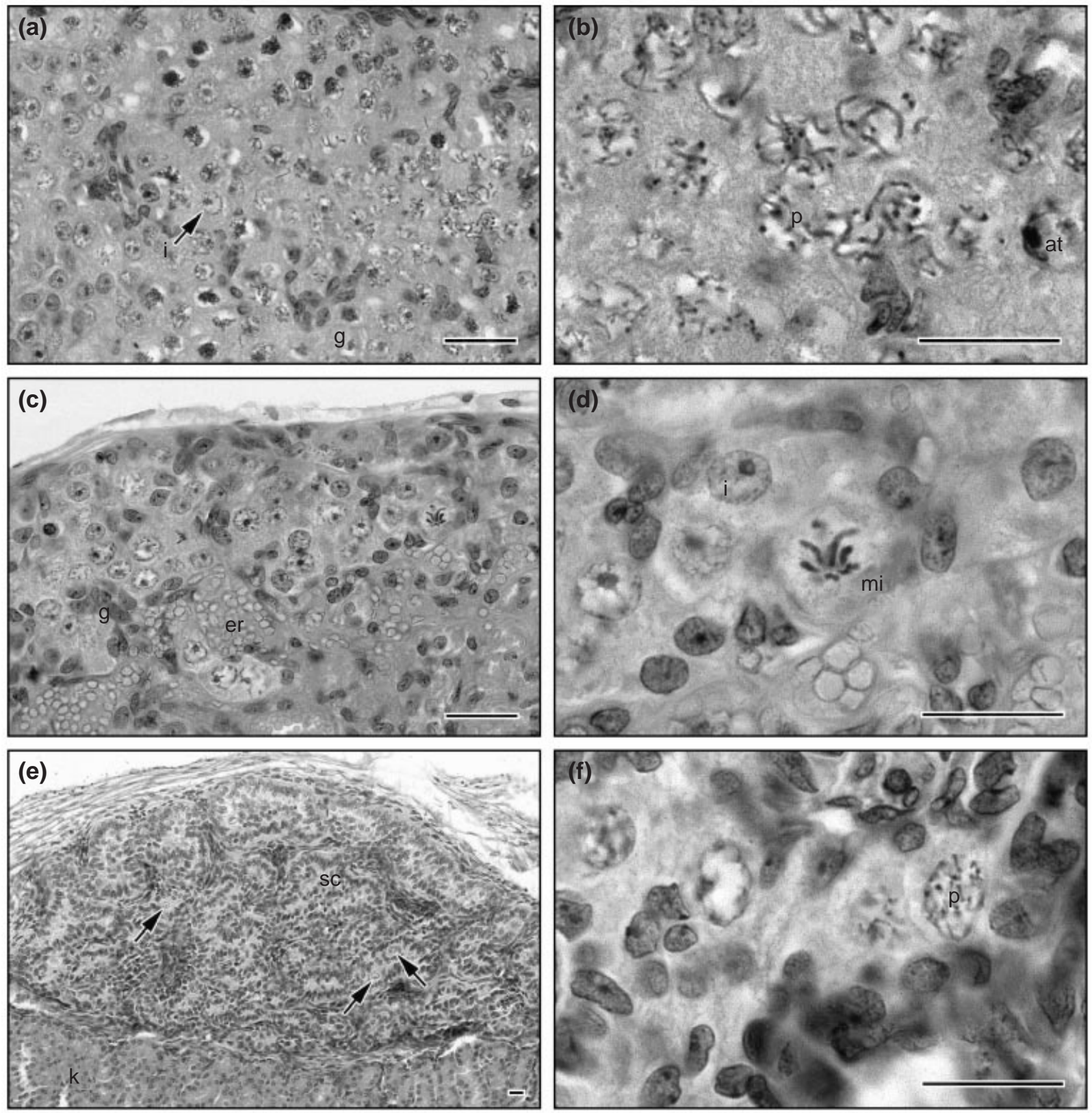

Fig. 1. Morphology of ovaries $(\mathrm{a}, \mathrm{b})$ from a control 50-day-old pouch young tammar wallaby, Macropus eugenii, (c,d) from a 20-day-old pouch young tammar wallaby at 8 weeks after grafting and (e,f) from a 20-day-old pouch young tammar wallaby at 21 weeks after grafting. $(a, b)$ Germ cells in the cortex of the control ovaries had entered prophase I of meiosis ( $p$ ) in areas nearest the medulla, whereas germ cells at the periphery remained in interphase (i). Atretic germ cells (at) were also present. $(\mathrm{c}, \mathrm{d})$ Eight weeks after grafting, germ cells were found in nests surrounded by pre-granulosa cells, and were most abundant in areas infiltrated by erythrocytes (er). Most germ cells remained in interphase (i) with some undergoing mitosis (mi). (e) At 21 weeks after grafting, somatic cells had become aligned into elongated tubules resembling seminiferous cords (sc), which contained Sertoli-like cells aligned along the basement membrane. A few germ cells in interphase (arrows) remained within the centre of the tubules. (f) In areas of grafts in which no tubules were found, a few remnant germ cells were found occasionally in prophase I of meiosis (p). g: pre-granulosa cells, k: kidney of the host. Scale bars represent $100 \mu \mathrm{m}$.

(Fig. 1a,b). Further development of follicles beyond the primordial stage started at about day 110 post partum when the granulosa cells become cuboidal and there was an increase in the number of layers surrounding the oocyte.
From day 150 to day 210 post partum there was a continual increase in the number of layers surrounding the oocyte, leading to the formation of the fluid filled antrum (Fig. 2a). During this stage, interstitial tissue differentiated from the 

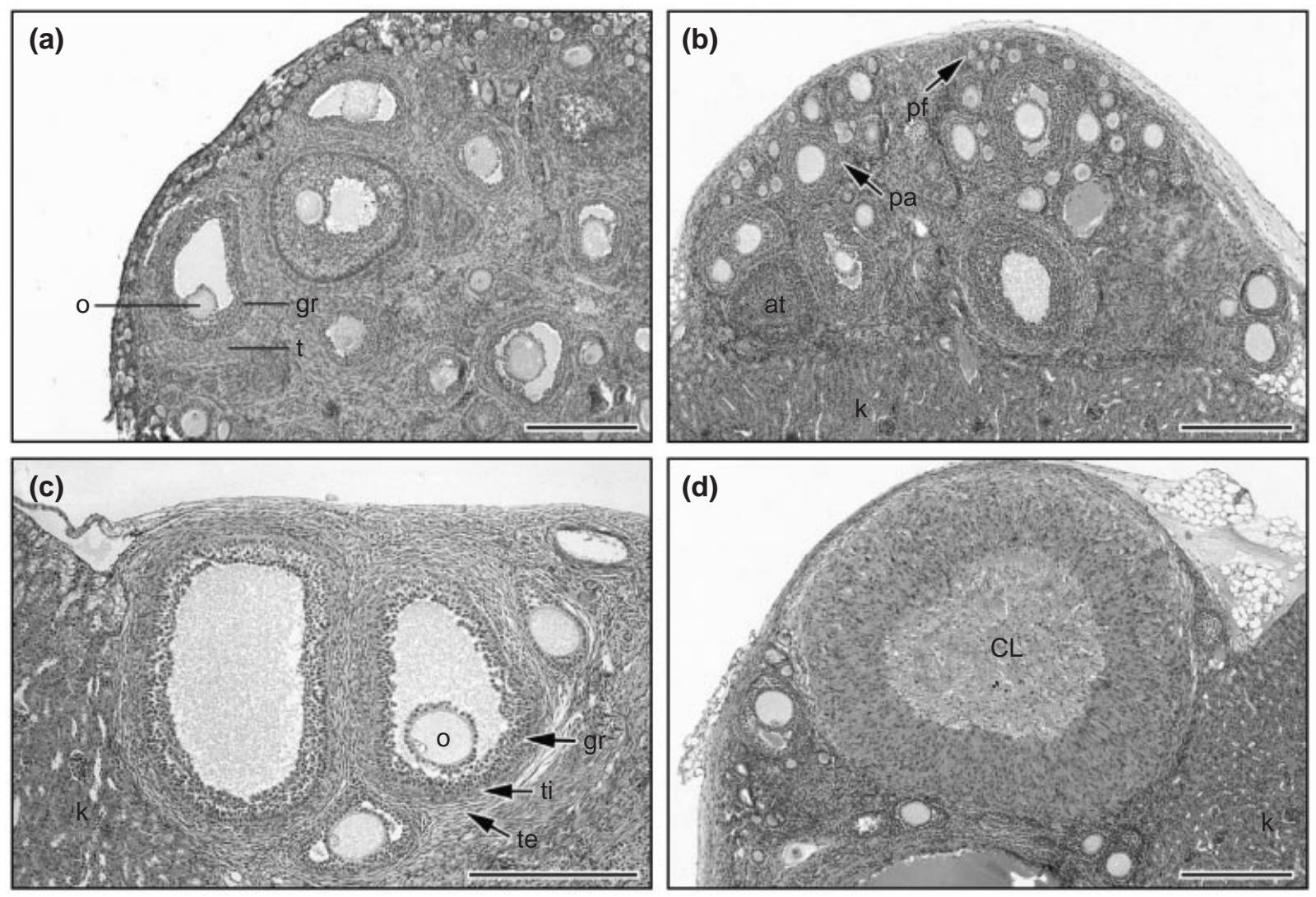

Fig. 2. Morphology of ovaries (a) from a control 150-day-old pouch young tammar wallaby, Macropus eugenii, (b) from a 50day-old pouch young tammar wallaby at 16 weeks after grafting and (c,d) from a 50-day-old pouch young tammar wallaby at 21 weeks after grafting. (a) Control ovaries contained primordial follicles, with a single layer of granulosa cells surrounding the oocyte (o); preantral follicles, with numerous layers of granulosa cells, and antral follicles, with distinct granulosa (gr) and thecal layers (t) surrounding a fluid filled antrum enclosing the oocyte (o). (b) At 16 weeks after grafting, ovarian tissue contained primordial (pf), preantral (pa) and antral follicles. Atretic follicles (at) can also be seen in the graft. (c) Large antral follicles formed 21 weeks after grafting. The fluid filled antrum is surrounded by both granulosa (gr) and theca interna (ti) and theca externa (te), and contains the oocyte (o) with distinct nucleus. (d) Corpus luteum (CL) forming in ovarian tissue 21 weeks after grafting. The luteal cells are made up from hypertrophied granulosa cells. No ovulation point was found. k: kidney of the host. Scale bars represent $1000 \mu \mathrm{m}$.

rete cords, forming a prominent part of the ovary. As described by Alcorn (1975), mesenchymal cell groups of the rete cords were dominated by the rounded secretory cells of the interstitial tissue, with the interstitial tissue becoming enlarged and lobular in appearance. At day 210 post partum, primordial, preantral and antral follicles were present. Adult ovaries contained follicles at all stages of development and included both corpora lutea and corpora albicans.

\section{Non-frozen ovarian grafts}

Of the 29 pieces of non-frozen ovarian tissue from both donor age groups that were grafted immediately into SCID mice, 27 grafts (93\%) survived and were developing within the recipient mouse. The two grafts that did not survive had large fluid filled cysts that compressed the graft into a thin layer around their circumference. No germ cells or follicles at any stage were evident within these cystic grafts. Both of these grafts were from pouch young that were $<20$ days old at the time of grafting and were grafted for 12 and 21 weeks.

Ovaries from pouch young which were $<20$ days old at the time of grafting that survived $(n=6)$ contained areas of germ cells and medulla. At 2 weeks after grafting, germ cells were present in nests surrounded by somatic cells. No distinct organization was observed in these surrounding somatic cells, nor was there a distinct separation between areas of germ cells and medulla. Blood vessels were evident in all grafts, particularly around clusters of germ cells, indicating that revascularization had been established. Most germ cells were in interphase and some germ cells entered mitosis 4 weeks after grafting. By week 8 after grafting (Fig. 1c,d), the grafts contained germ cells, most of which were in interphase, and pre-granulosa cells located around the periphery, and the occasional oocyte entered prophase 1 of meiosis. At week 16 after grafting, only small clumps of germ cells in interphase remained and were restricted to areas where germ cells had maintained a close 
Table 1. Number of follicles (mean $\pm \mathrm{SE}$ ) in non-frozen and frozen-thawed ovaries from day 50 pouch young of tammar wallabies (Macropus eugenii) at 2 and 21 weeks after grafting

\begin{tabular}{|c|c|c|c|c|}
\hline $\begin{array}{l}\text { Weeks after } \\
\text { grafting }\end{array}$ & $\begin{array}{c}\text { Number of } \\
\text { grafts }\end{array}$ & $\begin{array}{c}\text { Number of } \\
\text { primordial follicles }\end{array}$ & $\begin{array}{c}\text { Number of } \\
\text { preantral follicles }\end{array}$ & $\begin{array}{c}\text { Number of } \\
\text { antral follicles }\end{array}$ \\
\hline \multicolumn{5}{|l|}{ Non-frozen } \\
\hline 2 & 1 & 80 & 0 & 0 \\
\hline 4 & 3 & $44 \pm 7$ & $0 \pm 0$ & $0 \pm 0$ \\
\hline 8 & 3 & $52 \pm 37$ & $15 \pm 7$ & $0 \pm 0$ \\
\hline 12 & 3 & $84 \pm 44$ & $14 \pm 3$ & $1 \pm 1$ \\
\hline 16 & 4 & $203 \pm 58$ & $71 \pm 28$ & $11 \pm 7$ \\
\hline 18 & 3 & $290 \pm 46$ & $134 \pm 49$ & $2 \pm 1$ \\
\hline 21 & 4 & $233 \pm 132$ & $109 \pm 45$ & $6 \pm 1$ \\
\hline \multicolumn{5}{|l|}{ Frozen } \\
\hline 8 & 2 & $0 \pm 0$ & $0 \pm 0$ & $0 \pm 0$ \\
\hline 12 & 2 & $126 \pm 7$ & $12 \pm 6$ & $0 \pm 0$ \\
\hline 21 & 4 & $9 \pm 3$ & $25 \pm 15$ & $1 \pm 1$ \\
\hline
\end{tabular}

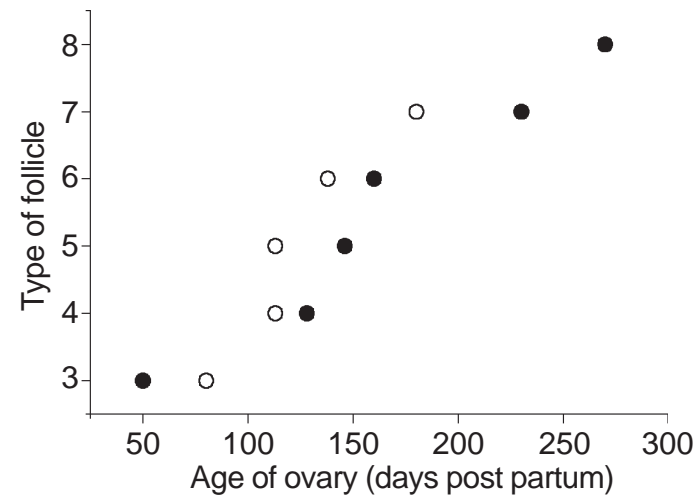

Fig. 3. Age of ovarian tissue in which follicles can be first identified in $(0)$ control and $(\bigcirc)$ grafted tissue in the tammar wallaby, Macropus eugenii. Types of follicle represent stages of follicular development as classified by Pedersen and Peters (1968). Once primordial follicles are established within the grafted tissue, development occurs at an accelerated rate to that observed in control ovaries.

association with blood vessels. Large areas of medulla remained and contained cells with darkly staining nuclei. These cells were often in mitosis. Atretic germ cells with tightly contracted chromatin were present in all grafts. No follicles of any type were found in any of the grafts, including a graft that was in the host for 21 weeks.

Two ovarian grafts from pouch young $<20$ days of age at the time of grafting, and with the longest intervals of 18 and 21 weeks after surgery, contained areas showing a distinct lack of germ cells. Within these regions were several structures resembling seminiferous cords (Fig. 1e). These elongated tubules were composed of somatic cells, which had aligned to form columnar epithelium with basal nuclei and cytoplasm extending into the lumen, although a distinct, open lumen was not present. In some areas peritubular myoid-like cells could be seen perpendicular to the columnar cells lining the tubules. A few remnant germ cells were present within the lumen of the tubules, and these remained in interphase. A few germ cells were scattered in other areas of the grafts but only where the tissue displayed distinct ovarian development. Occasionally, these germ cells appeared to be in prophase 1 of meiosis (Fig. 1f).

Ovarian grafts from pouch young $>50$ days old at the time of grafting $(n=21)$ contained follicles from primordial stages to large antral follicles and corpora lutea (Table 1). Primordial follicles were observed 2 weeks after grafting, and preantral follicles were first observed 8 weeks after grafting. Grafts collected after week 16 contained primordial, preantral and antral follicles (up to type 7), all of which were similar in morphology to follicles found in the control adult ovaries (Fig. 2b,c). Two distinctive thecal cell layers, theca interna and theca externa, were observed in all multilaminar follicles. Mitotic figures were observed in granulosa cells, indicating that these follicles were still growing. No preovulatory follicles (type 8) were found in any of the grafts recovered, even 21 weeks after surgery (Table 1). However, corpora lutea were found in ovarian tissue from all seven grafts recovered after 21 weeks (Fig. $2 \mathrm{~d}$ ) indicating that follicles had reached maturity before undergoing luteinization. Atretic follicles were also observed in all grafts, with degeneration of the oocytes accompanied by disruption of granulosa cell layers and granulosa cells with pyknotic nuclei. As in the grafts from younger pouch young, some grafts $(n=2)$ contained fluid filled cysts. These cysts were lined with a single layer of cells, and oocytes and granulosa cells were not observed within the cyst.

Initially, the development of primordial follicles was observed only after day 80 within grafted tissue, but once primordial follicles were present, development to preantral follicles progressed rapidly (Fig. 3). Early antral follicles (type 6) were initially present 12 weeks after grafting, and type 7 follicles were present at least 7 weeks earlier than in control ovaries. 

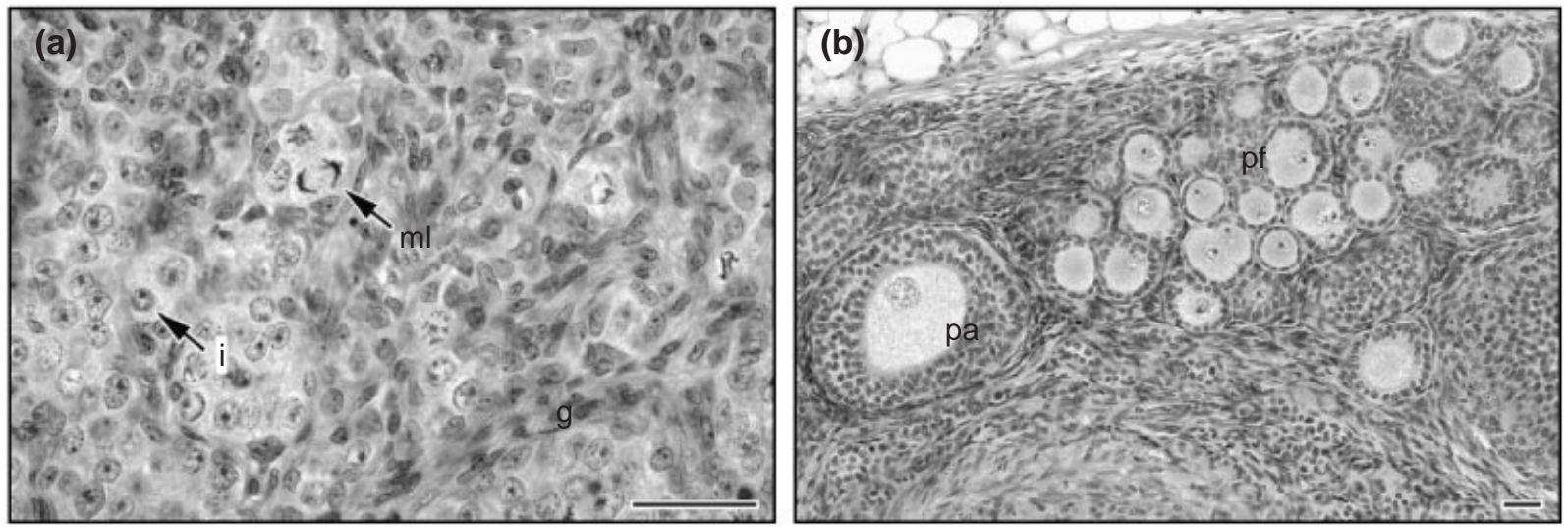

Fig. 4. Morphology of frozen-thawed ovaries from (a) a 20-day-old pouch young tammar wallaby, Macropus eugenii, 4 weeks after grafting and from (b) a 50-day-old pouch young tammar wallaby 12 weeks after grafting. (a) Numerous germ cell nests are present separated by pre-granulosa cells (g). Most germ cells are in interphase (i), and mitotic activity (mi) was also observed. (b) Twelve weeks after grafting, frozen-thawed tissue contained both primordial (pf) and preantral (pa) follicles. Scale bars represent $100 \mu \mathrm{m}$.

\section{Cryopreserved ovarian grafts}

All but one graft of cryopreserved ovaries survived. The failed graft was from a pouch young $>50$ days of age and had the longest post-operative interval of all frozen-thawed tissue (21 weeks).

All cryopreserved grafts from pouch young $<20$ days of age at the time of grafting $(n=7)$ contained numerous germ cells located in nests and separated by stroma (Fig. 4a). Blood vessels were also present indicating that revascularization had occurred. As with the non-frozen grafts, germ cells maintained a close association with these areas of blood vessels and, despite the presence of germ cells, follicles were not found in any of these grafts. Most germ cells were in interphase and some germ cells entered mitosis as early as 2 weeks after grafting. Mitotic activity was also often observed in surrounding somatic cells.

Ovaries collected from pouch young $>50$ days of age at the time of grafting $(n=7)$ contained large, sometimes haemorrhagic follicles. Development of both primordial and preantral follicles was not observed until week 12 after grafting (Fig. 4b), compared with week 2 and week 8, respectively, in non-frozen tissue (Table 1). Development of follicles continued up to late preantral stages and early antral follicles (type 6) 21 weeks after grafting, but no corpora lutea were observed. In comparison, non-frozen tissue of the same age contained both large antral follicles (type 7) and corpora lutea.

\section{Oocyte collection}

Oocytes were collected only from recipients of grafts from non-frozen 50-70-day-old pouch young at $>16$ weeks after surgery. In total, 25 oocytes and six empty zona pellucida were obtained from 12 grafts. Seven of the eggs appeared to be immature with a small diameter $(113 \pm 6 \mu \mathrm{m})$ and few adhering cumulus cells. Four oocytes showed signs of atresia and had collapsed zonae pellucidae and dark condensed cytoplasm at the time of collection. These atretic oocytes and the empty zonae pellucidae were found only in grafts collected from mice 21 weeks after surgery. The remaining 14 oocytes appeared normal and had a defined zona pellucida (Fig 5). The average size of these oocytes was $165 \pm 6 \mu \mathrm{m}$. Six of these oocytes were retrieved from grafts at 16 weeks after surgery, whereas four oocytes were retrieved from each group of grafts at 18 and 21 weeks after surgery. Most oocytes that were recovered had no cumulus cells. One oocyte was surrounded by cumulus but this was very loosely attached and was dislodged on recovery from the graft. No oocytes had a visible polar body at the time of recovery.

\section{FSH concentrations}

Plasma samples collected from intact control mice had significantly lower FSH concentrations $\left(2.8 \pm 0.4 \mathrm{ng} \mathrm{ml}^{-1}\right)$ than did those from ovariectomized control mice $\left(19.9 \pm 0.7 \mathrm{ng} \mathrm{ml}^{-1} ; P<0.05\right)$. Plasma samples collected from graft recipients had low FSH concentration (5.3 \pm 0.8 $\mathrm{ng} \mathrm{ml}^{-1}$ ) comparable with those of intact female mice. There was a significant difference between the concentrations of FSH in intact and ovariectomized control animals $(t=26.0$, $P=0.001)$, and between grafted and ovariectomized control mice $(t=-9.09, P=0.001)$, but no significant difference between grafted and intact control mice $(t=1.54, P=0.16)$.

\section{Analysis of uterine tissue}

The uteri from intact control mice had thick myometrial layers and columnar endometrial luminal and glandular epithelium (Fig. 6a), whereas the uteri of ovariectomized mice had thin myometrial layers and dilated fluid filled glands (Fig. 6b). The epithelium of the lumen was cuboidal and the stroma contained much less cellular material. All 


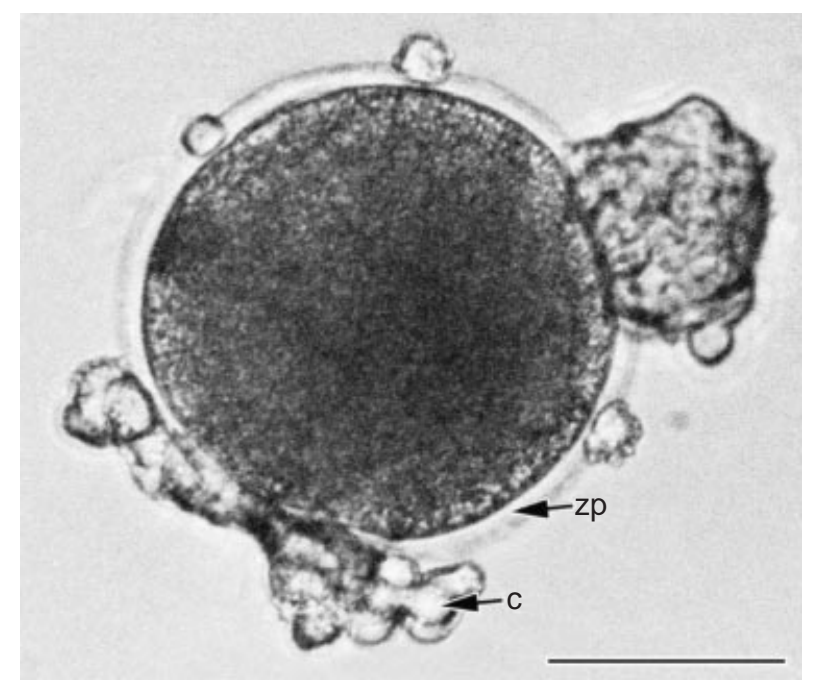

Fig. 5. An oocyte released from ovarian tissue from a 50-day-old pouch young of tammar wallaby, Macropus eugenii, grafted for 21 weeks in the recipient mouse. The dark cytoplasm is surrounded by a well-defined zona pellucida (zp) and a few cumulus cells (c) remain attached to the zona. Scale bar represents $80 \mu \mathrm{m}$.

mice with ovarian grafts that had developed preantral and antral follicles had uteri with thick layers of myometrium, stimulated glands and cellular stromal tissue (Fig. 6c). Mice with ovarian grafts that had not developed follicles had uteri similar to those seen in ovariectomized mice, with thin myometrial layers and fluid filled glands (Fig. 6d).

\section{Discussion}

This is the first study to demonstrate that folliculogenesis up to the development of large antral follicles can be achieved in immature marsupial ovaries after xenografting to immunologically compromised mice. Ovarian tissue transplanted into mice developed and became morphologically similar to a normal adult ovary containing follicles at all developmental stages. These grafts demonstrated endocrine activity and in some cases formed corpora lutea. In addition, ovarian grafts from pouch young of the tammar wallaby were able to develop follicles up to early antral stages after cryopreservation.

The freshly transplanted ovarian tissue collected from pouch young between day 50 and day 70 post partum had a similar appearance to that of normal tammar wallaby ovaries when examined histologically. Revascularization of the graft had occurred, providing an adequate supply of nutrients for continued development of ovarian follicles and stromal tissue. The kidneys were chosen for the position of grafting for their rich vascular supply (Sherwood, 1989) and increased concentration of angiogenic growth factors (Jakeman et al., 1992). Complete follicular development from primordial follicles to corpora lutea was seen in transplanted tissue. Although the majority of follicles were primordial, preantral and antral follicles were also present.
The initial density and total number of follicles present before grafting was not consistent as pieces of ovarian tissue were used instead of whole ovaries; therefore, it is inaccurate to compare absolute number of follicles. However, the data indicate that more preantral and antral follicles were present in tissue after longer grafting intervals, as more follicles were recruited.

No grafts displayed large amounts of atresia or reabsorption of the ovarian tissue; however, the appearance of several large cysts in ovaries after the longest grafting intervals indicates that the ovarian tissue may not be able to function for an extended period. In mouse and rat ovarian tissue grafted to spleen or connective tissue, cysts formed after implantation intervals of several months, and this cystic development was attributed to inadequate vascularization (Parkes, 1956; Krohn, 1962; Desjardins and Brawer, 1989). Cysts in ovarian grafts are also attributed to increased gonadotrophic stimulation resulting from ovariectomy of the recipient (McGowan and Davis, 1970) and retained follicular fluid within the connective tissue of the graft (Quattropani, 1984). In orthotopic transplantation, adhesions between the capsular membrane and the surface of the ovary can develop. As fluids, blood and ova are trapped within these adhesions, large distended cysts are formed (Jones and Krohn, 1960). As cysts did not develop during the shorter periods of grafting in the present study, and FSH concentrations were not high when the grafts were retrieved, the cysts observed were probably attributable to inadequate vascularization and trapped fluids within adhesions. In addition, the kidney epithelium may not dissolve or disaggregate to allow the oocyte to pass, as occurs with ovarian epithelium at the time of ovulation.

Ovarian tissue from pouch young matured at an accelerated rate after transplantation, as has been reported for several other species (for a review, see Nugent et al., 1997). The hormonal environment of the recipient may be responsible for increasing the rate of development of the transplanted ovary. Ovariectomy of recipient mice resulted in a significant increase in FSH concentrations. Cox et al. (2000) showed that fetal and neonatal mouse ovaries display normal ovarian function after transplantation to bilaterally ovariectomized recipients, but that antral follicle formation was impaired after transplantation to intact recipients. These workers also suggested that the high FSH content observed in bilaterally ovariectomized recipients may play a role in supporting follicular development in transplanted fetal and early neonatal ovaries.

No follicles were found in grafts derived from pouch young $<20$ days of age, even in tissue that had been grafted for 120 days. In these grafts, there was a decrease in the number of germ cells, or they were absent altogether, and in areas devoid of germ cells the tissue had taken on the appearance of seminiferous tubules. In eutherian mammals, loss of germ cells in the ovary can lead to the formation of seminiferous cords. Both rat (Byse, 1935) and mouse (Taketo, 1991; Taketo et al., 1993) fetal ovaries can be induced to form testicular cords after transplantation into 

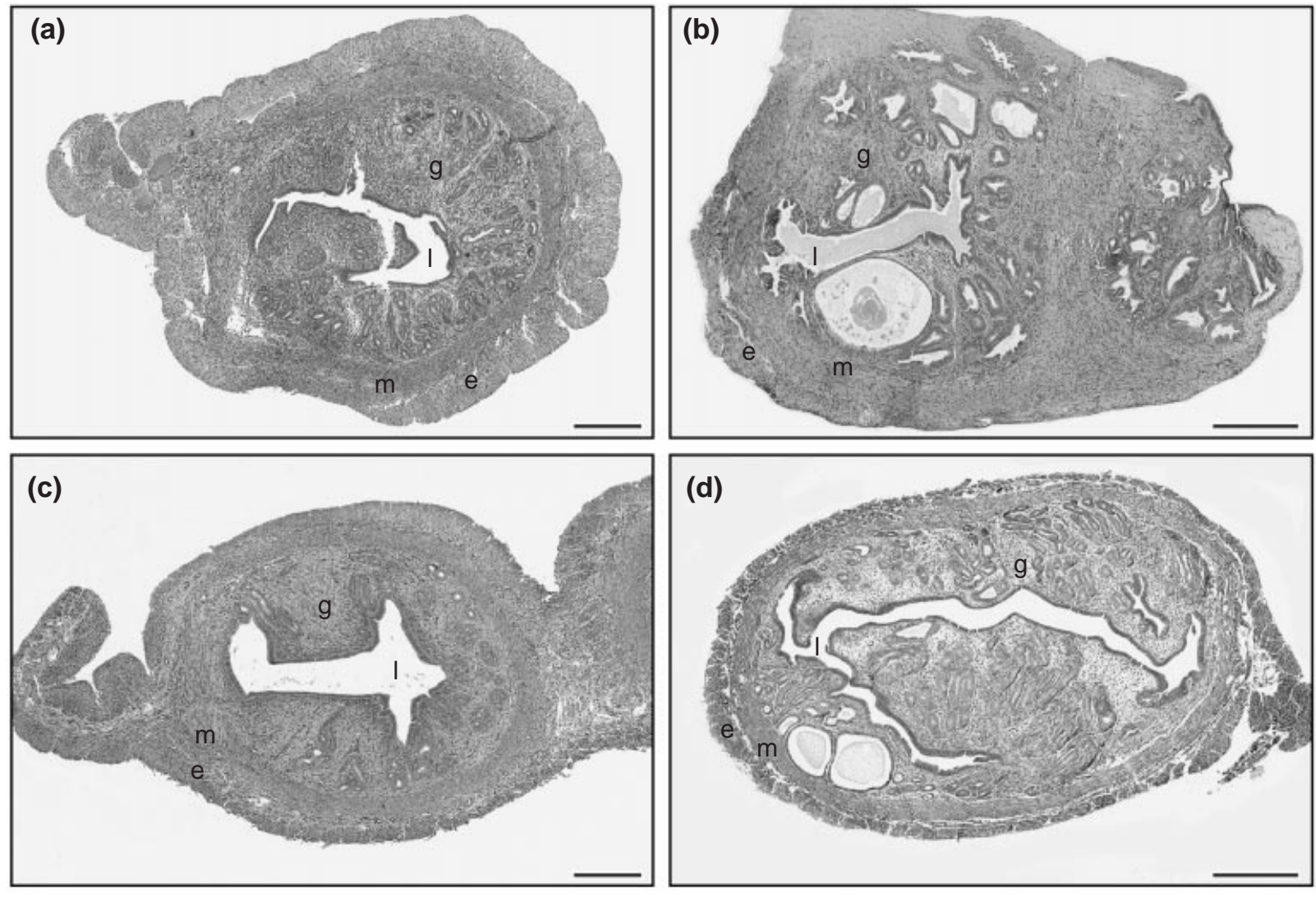

Fig. 6. Transverse sections of mouse uteri from (a) control intact, (b) control ovariectomized and (c,d) recipients of grafts containing (c) antral follicles and (d) germ cells only. (a,c) Uteri of graft recipients that contained antral follicles resemble those of control intact mice with thick myometrial layers $(\mathrm{m})$, healthy glandular stroma $(\mathrm{g})$ and columnar epithelium of the lumen (I). $(b, d)$ Uteri of graft recipients that contained only germ cells resembled the uteri of ovariectomized control mice with thin myometrial layers, dilated, fluid filled glands in the stroma and cuboidal epithelium of the lumen. e: endometrium. Scale bars represent $1000 \mu \mathrm{m}$.

either female or male hosts. Similarly, ovarian tissue from the tammar wallaby undergoes a loss of germ cells and formation of seminiferous tubules after transplantation to male recipients or culture with recombinant Mullerianinhibiting substance (Whitworth et al., 1996). If germ cells are lost after they have entered meiosis, pre-follicle cells surrounding the oocyte are capable of transforming into Sertoli-like cells (McLaren, 1991). However, Whitworth et al. (1996) argued that the loss of mitotic germ cells is sufficient to cause ovarian sex reversal. Changes resembling sex reversal in the present study were observed after a loss of both meiotic and pre-meiotic cells, indicating that prefollicular cells within ovaries were capable of differentiation into Sertoli-like cells and were able to form structures resembling seminiferous tubules. Sertoli cell differentiation may not be restricted to ovaries in which the germ cells have already reached the oocyte stage, as suggested by Taketo-Hosotani et al. (1985), and may not require the presence of a male influence. It has been suggested that the direct contact between the graft and the host kidney is essential for the induction of XX testicular differentiation (Taketo et al., 1993). However, it remains unknown whether this interaction is causing the loss of oocytes or providing a factor required for differentiation of Sertoli cells.

Although non-frozen ovarian tissue survived transplantation and developed to a stage in which preantral and large antral follicles were present, early antral follicles were not present in cryopreserved tissue until 21 weeks after grafting. Primordial follicles were first observed 12 weeks after grafting, compared with just 2 weeks in non-frozen tissue, and despite the fact that primordial follicles were present before grafting. The total number of follicles obtained from the frozen-thawed grafts also appeared to be lower than in non-frozen tissue. These results indicate that some loss of germ cells or follicles occurred as a direct result of the cryopreservation. This finding is in agreement with studies in other species in which the number of follicles within transplanted ovaries after cryopreservation was found to be significantly lower than in non-frozen transplanted ovaries (Shaw et al., 2000). The absence of follicles at 8 weeks after grafting indicates a loss of primordial follicles after cryopreservation, and that developing follicles observed at 12 weeks are most likely to have developed from immature female germ cells present at cryopreservation. However, 
despite this delay in development, the follicles appeared healthy, and showed no signs of degeneration of the oocyte and mitotic activity in granulosa cells, indicating that these follicles were still growing. The reduced number of follicles present at 21 weeks after grafting, especially primordial follicles, suggests that the ovarian tissue may have exhausted its pool of potential follicles, due to the marked loss of follicles after cryopreservation.

The recovered oocytes were of comparable size to oocytes recovered from ovaries in situ $(152 \pm 10 \mu \mathrm{m}$ : Renfree and Lewis, 1996), and had dark cytoplasm that is characteristic of marsupial oocytes (Tyndale-Biscoe and Renfree, 1987). In all marsupial species observed so far the cumulus cells surrounding the oocyte become detached before ovulation (Breed, 1996), resulting in cumulus-free oocytes as observed in the present study. Although the developmental potential of these oocytes was not investigated in this study, the apparently normal morphology of oocytes indicates that marsupial oocytes recovered from ovarian xenografts are capable of maturation. Further studies involving in vitro maturation and fertilization of these oocytes would confirm their developmental competence. The appearance of atretic oocytes and empty zonae pellucidae at 21 weeks after grafting indicates that oocytes required for in vitro fertilization should be collected at about 18 weeks after grafting.

The uteri of the host mice provided a crude bioassay for hormone production by the grafts, as the natural ovaries of the recipient had been removed. Where the ovarian transplants contained only germ cells, oestrogen production would have been minimal. This was confirmed by the uteri of the recipients of these grafts, which were similar to the uteri of ovariectomized animals. In contrast, the uteri were stimulated in animals that had established grafts containing preantral and antral follicles, confirming that the grafts had developed to a stage at which they were able to produce oestrogens. Analysis of mouse uterine tissue supported the results from the FSH assay. All animals with low concentrations of $\mathrm{FSH}$ had stimulated uteri with thick layers of myometrium and stimulated glands. All these recipients had low circulating concentrations of FSH similar to those in intact control mice. These results indicate that the hormones from the wallaby ovarian tissue were exerting a negative feedback effect on the mouse pituitary.

Development of follicles in grafted tissue demonstrates that ovaries from tammar wallaby pouch young are capable of normal function after cryopreservation and transplantation into adult mice. Further studies are needed to optimize cryopreservation procedures in order to reduce the number of follicles lost after cryopreservation. These techniques have the potential to be used as methods for preserving genetic material and can also help contribute to our understanding of sexual development in marsupials.

The authors wish to thank P. Jackson for help with animal handling, A. O'Connor and S. Hayward for running the FSH assays and D. Paul for assistance with photography. Tammar wallabies were collected under permits from South Australia and of National Parks and Wildlife, and held under permit number RP-95-088 of the Department of Natural Resources and Environment, Victoria.

\section{References}

Alcorn GT (1975) The Development of the Ovary and Urogenital Ducts of the Tammar Wallaby, Macropus eugenii. PhD Thesis, Macquarie University, Sydney, Australia

Baird D, Webb R, Campbell B, Harkness L and Gosden R (1999) Long-term ovarian function in sheep after ovariectomy and transplantation of autografts stored at $-196^{\circ} \mathrm{C}$ Endocrinology $\mathbf{1 4 0} 462-471$

Breed W (1996) Egg maturation and fertilization in marsupials Reproduction, Fertility and Development 8 617-643

Byse A (1935) The differentiation of transplanted mammalian gonad primordia Journal of Experimental Zoology 70 1-41

Candy C, Wood M and Whittingham D (1995) Follicular development in cryopreserved marmoset ovarian tissue after transplantation Human Reproduction $102334-2338$

Candy C, Wood M and Whittingham D (1997) The effect of cryoprotectants on the survival of follicles in frozen mouse ovaries Journal of Reproduction and Fertility $11011-19$

Carroll J, Whittingham D, Wood M, Telfer E and Gosden R (1990) Extraovarian production of mature viable mouse oocytes from frozen primary follicles Journal of Reproduction and Fertility $90321-327$

Cox S, Shaw J and Jenkin G (1996) Transplantation of cryopreserved fetal ovarian tissue to adult recipient mice Journal of Reproduction and Fertility $10315-322$

Cox S-L, Shaw J and Jenkin G (2000) Follicular development in transplanted fetal and neonatal mouse ovaries is influenced by the gonadal status of the adult recipient Fertility and Sterility 74 366-371

Desjardins G and Brawer J (1989) Development and maintenance of a polycystic condition in ovaries autotransplanted under the kidney capsule Anatomical Record 225 118-123

Gook D, Edgar D and Stern C (1999) Effect of cooling rate and dehydration regimen on the histological appearance of human ovarian cortex following cryopreservation in 1,2-propanediol Human Reproduction 14 2061-2068

Gosden R (1990) Restitution of fertility in sterilized mice by transferring primordial ovarian follicles Human Reproduction 5 499-504

Gosden R (1992) Transplantation of ovaries and testes. In Fetal Tissue Transplants in Medicine pp 253-273 Ed. R Edwards. Cambridge University Press

Gosden R (2000) Low temperature storage and grafting of human ovarian tissue Molecular and Cellular Endocrinology 163 125-129

Gosden R, Boulton M, Grant K and Webb R (1994) Follicular development from ovarian xenografts in SCID mice Journal of Reproduction and Fertility 101 619-623

Gunasena K, Lakey J, Vilines P, Bush M, Raath C, Critser E, McGann L and Critser J (1998) Antral follicles develop in xenografted cryopreserved African elephant (Loxodonta africana) ovarian tissue Animal Reproduction Science 53 265-275

Gunderson HJG, Bendtsen TF, Korbo L et al. (1988a) The new stereological tools: dissector, fractionator, nucleator and point sampled intercepts and their use in pathological research and diagnosis APMIS 96 857-881

Gunderson HJG, Bendtsen TF, Korbo L et al. (1988b) Some new, simple and efficient stereological methods and their use in pathological research and diagnosis APMIS 96 379-394

Hopwood D (1996) Fixation and fixatives. In Theory and Practice of Histological Techniques 3rd Edn pp 21-42 Eds J Bancroft and A Stevens. Churchill Livingstone, Edinburgh

Jakeman L, Winer J, Bennett G, Altar C and Ferrara N (1992) Binding sites for vascular endothelial growth factors are localised on endothelial cells in adult rat tissue Journal of Clinical Investigation 89 244-253

Jenkin G, Cox S-L and Shaw J (1996) Transplantation of fetal ovarian tissue Singapore Journal of Obstetrics and Gynecology 27 85-91

Jones E and Krohn P (1960) Orthotopic ovarian transplantation in mice Journal of Endocrinology 20 135-146 
Krohn P (1962) Transplantation of the ovary. In The Ovary II pp 435-446 Ed. S Zuckerman. Academic Press, New York

Lara H, Dees W, Hiney J, Dissen G, Rivier C and Ojeda S (1991) Functional recovery of the developing rat ovary after transplantation: contribution of the extrinsic innervation Endocrinology 129 1849-1860

McGowan L and Davis R (1970) Intrasplenic ovarian grafts in Syrian hamsters and periotoneal fluid cellular distribution Experimental Biology and Medicine 134 507-509

McLaren A (1991) Development of the mammalian gonad: the fate of the supporting cell lineage BioEssays 13 151-156

Newton H, Aubard Y, Sharma V, Rutherford A and Gosden R (1996) The low temperature storage and grafting of human ovarian tissue into SCID mice Human Reproduction 11 1487-1491

Newton H, Picton H and Gosden R (1999a) In vitro growth of oocyte-granulosa cell complexes isolated from cryopreserved ovine tissue Journal of Reproduction and Fertility 115 141-150

Newton H, Pegg D, Barrass R and Gosden R (1999b) Osmotically inactive volume, hydraulic conductivity and permeability to dimethyl sulphoxide of human mature oocytes Journal of Reproduction and Fertility 117 27-33

Nugent D, Meirow D, Brook P, Aubard T and Gosden R (1997) Transplantation in reproductive medicine - previous experience, present knowledge and future prospects Human Reproduction Update 3 $267-280$

Oktay K, Newton H, Mullan J and Gosden R (1998a) Development of human primordial follicles to antral stages in SCID/hpg mice stimulated with follicle stimulating hormone Human Reproduction 13 1133-1138

Oktay K, Newton H, Aubard Y, Salha O and Gosden R (1998b) Cryopreservation of immature human oocytes and ovarian tissue: an emerging technology? Fertility and Sterility 69 1-7

Parkes A (1956) Survival time of ovarian homografts in two strains of rats Journal of Endocrinology 13 201-210

Pedersen T and Peters H (1968) Proposal for a classification of oocytes and follicles in the mouse ovary Journal of Reproduction and Fertility $\mathbf{1 7}$ 555-557

Poole W, Simms N, Wood J and Lubulwa M (1991) Tables for age determination of the Kangaroo Island wallaby (Tammar) Macropus eugenii from body measurements CSIRO Technical Memorandum 32, CSIRO Division of Wildlife and Ecology, Canberra, Australia

Quattropani S (1984) Ovulation of ovarian implants in unilaterally ovariectomised rats Anatomical Record 209 331-336

Radford JA, Lieberman BA, Brison DR and Smith ARB (2001) Orthotopic reimplantation of cryopreserved ovarian cortical strips after high-dose chemotherapy for Hodgkin's lymphoma The Lancet 357 1172-1175

Renfree M and Lewis A (1996) Cleavage in vivo and in vitro in the marsupial Macropus eugenii. Reproduction, Fertility and Development 8 725-742

Salle B, Lornage J, Demirci B, Vaudoyer F, Poirel M, Franck M, Rudigoz R and Guerin J (1999) Restoration of ovarian steroid secretion and histologic assessment after freezing, thawing and autograft of a hemiovary in sheep Fertility and Sterility 72 366-370

Shaw J, Cox S-L, Trounson A and Jenkin G (2000) Evaluation of the longterm function of cryopreserved ovarian grafts in the mouse, implications for human applications Molecular and Cellular Endocrinology $\mathbf{1 6}$ $103-110$

Sherwood I (1989) Urinary systems. In Human Physiology From Cells to Systems 3rd Edn pp 468-514. Wadsworth Publishing Company, USA
Spears N, de Bruin J and Gosden R (1996) The establishment of follicular dominance in co-culture mouse ovarian follicles Journal of Reproduction and Fertility 106 1-6

Stevens A (1996) The haematoxylins. In Theory and Practice of Histological Techniques 3rd Edn pp 107-118 Eds J Bancroft and A Stevens. Churchill Livingstone, Edinburgh

Taketo T (1991) Production of Mullerian-inhibiting substance (MIS) and sulfated glycoprotein-2 (SGP-2) associated with testicular differentiation in the XX mouse gonadal graft Annals of the New York Academy of Sciences 637 74-89

Taketo T, Saeed J, Manganora T, Takahashi M and Donahoe PK (1993) Mullerian inhibiting substance production associated with loss of oocytes and testicular differentiation in the transplanted mouse XX gonadal primordium Biology of Reproduction 49 13-23

Taketo-Hosotani T, Merchant-Larios H, Thau R and Koide S (1985) Testicular cell differentiation in fetal mouse ovaries following transplantation into adult male mice Journal of Experimental Zoology 236 229-237

Telfer E, Torrance C and Gosden R (1990) Morphological study of cultured preantral ovarian follicles of mice after transplantation under the kidney capsule Journal of Reproduction and Fertility 89 565-571

Tyndale-Biscoe H and Renfree M (1997) Reproductive Physiology of Marsupials Cambridge University Press, Cambridge

Ullmann S, Shaw G, Alcorn G and Renfree M (1997) Migration of primordial germ cells to the developing gonadal ridges in the tammar wallaby Macropus eugenii. Journal of Reproduction and Fertility $\mathbf{1 1 0}$ 135-143

Van der Elst J, Merinckx S and Van Steirteghen A (1992) In vitro maturation of mouse germinal vesicle-stage oocytes following cooling exposure to cryoprotectants and ultra-rapid freezing: limited effect on the morphology of the second meiotic spindle Human Reproduction 7 1440-1446

Weibel E (1979) Stereological Methods Academic Press, London

Weissman A, Gotlieb L, Colgan T, Jurisicova A, Greenblatt E and Casper R (1999) Preliminary experience with subcutaneous human ovarian cortex transplantation in the NOD-SCID mouse Biology of Reproduction $\mathbf{6 0}$ 1462-1467

Whitworth D, Shaw G and Renfree M (1996) Gonadal sex reversal of the developing marsupial ovary in vivo and in vitro. Development 122 4057-4063

Wolfe B and Wildt D (1996) Development to blastocysts of domestic cat oocytes matured and fertilized in vitro after prolonged cold storage Journal of Reproduction and Fertility 106 135-141

Wolvekamp MCJ, Cleary ML, Cox SL, Shaw JM, Jenkin G and Trounson AO (2001) Follicular development in cryopreserved common wombat ovarian tissue xenografted to nude rats Animal Reproduction Science $\mathbf{6 5}$ 135-147

Wreford N, O'Connor A and De Kretser D (1994) Gonadotropinsuppressing activity of human recombinant inhibin in the male rat is age dependent Biology of Reproduction 50 1066-1071

Received 21 June 2001

First decision 30 August 2001.

Accepted 28 September 2001 